\title{
Prospective study of pressure ulcer risk in spinal cord injury patients
}

\author{
G P Rodriguez PhD, S L Garber MA OTR
}

Physical Medicine and Rehabilitation Department, Baylor College of Medicine, The Institute for Rehabilitation and Research, 1333, Moursund Avenue, Houston, Texas 77030, USA.

Sixty men with spinal cord injury who had developed pressure ulcers in the past but whose skin was intact when they joined the study were followed for 2 years, or until a pressure ulcer developed. Forty of the men were contacted every 4-6 weeks to answer questions about their skin care practices and to provide a 24 hour urine sample. The others were only contacted at the beginning and the end of the study to answer a questionnaire and to provide a urine sample. Changes in skin collagen metabolism were monitored by measuring urinary excretion of a metabolite, glucosyl-galactosyl hydroxylysine (glu-gal Hyl), corrected for creatinine excretion. Sustained increases in levels of glu-gal Hyl excretion were detected at least 2 months and as much as 5 months in advance of overt clinical signs of ulcer development. Increased excretion of glu-gal Hyl was significantly associated $(p<0.05)$ with the development of a pressure ulcer. An increase in the urinary excretion of glu-gal $\mathrm{Hyl}$ is an indication of increased degradation of skin collagen. Body mass index (weight $/$ height $^{2}$ ) of $33 \%$ of subjects with pressure ulcers, and $12 \%$ of those without, was at least one standard deviation below the mean of all subjects. Thirty-six percent of those who smoked developed ulcers, while only $26 \%$ of the nonsmokers did. The majority of the subjects who developed ulcers had injury levels above T6. Present age and time since injury were similar among those subjects who developed ulcers and those who did not. Subjects who developed ulcers were more likely to be unemployed, not attending school, and to have had a greater number of ulcers previously. There was no statistically significant difference between subjects who developed a pressure ulcer and those who did not with regard to beliefs about risk or severity of pressure ulcers and about the relative importance of various pressure ulcer prevention strategies. The data indicate that biochemical indicators, such as urinary excretion of glu-gal $\mathrm{Hyl}$, and specific behavioral factors can be used to identify subjects at risk for developing pressure ulcers in time to institute vigorous preventative procedures to avoid skin breakdown.

Keywords: pressure ulcers; spinal cord injury; collagen; health beliefs.

\section{Introduction}

Pressure ulcers continue to be a serious complication for persons with spinal cord injury. It is variously estimated that between $50 \%$ and $80 \%$ of persons with spinal cord injury develop a pressure ulcer at least once in their lives. ${ }^{1-3}$ Pressure ulcers are very costly, the latest estimate being $\$ 60,000$ for treating them surgically. ${ }^{4}$ Following discharge from the rehabilitation center, persons with spinal cord injury are at an even greater risk when, attempting to be independent, employed, or involved in education, they may neglect to follow even the most basic skin care regimen taught to them during hospitalization. The majority of the ulcers appear to occur in the first 2 years after injury, but even 3 or 4 years after injury there is a reported incidence of $30 \% .^{3}$

Contemporary rehabilitation approaches to pressure ulcer management emphasize prevention of their recurrence. ${ }^{5-7}$ Particular 
stress is placed upon the early detection of impending skin breakdown and the initiation immediately of appropriate remedial actions. $^{8.9}$ An observational, prospective cohort study was conducted to assess the efficacy of a biochemical indicator and certain behavioral parameters to predict and/or prevent the development of recurrent pressure ulcers in persons with spinal cord injury. Collagen is the principal protein of the skin matrix and is responsible for the great tensile strength of skin. The collagen metabolism of spinal cord injured patients is altered following trauma. Collagen degradation is significantly increased. ${ }^{10.11}$ Glucosylgalactosyl hydroxylysine (Glu-gal Hyl) is a collagen metabolite. Its presence in large concentrations is the urine denotes the preferential degradation of skin collagen. ${ }^{12-15}$ This increased excretion has been associated with the presence of pressure ulcers. In patients from whom several samples were obtained, the increase preceded the overt signs of an ulcer ${ }^{16}$ by at least a month. In the present study, the urinary excretion of gly-gal $\mathrm{Hyl}$ and another collagen metabolite, galactosyl hydroxylysine, (gal Hyl), was closely monitored for 2 years in order to ascertain whether the urinary concentration of these two collagen metabolites could be used as indicators of pressure ulcer risk.

Current pressure ulcer prevention programs emphasize a combination of specific activities which, when carried out on a regular basis, are intended to reduce the risk and the recurrence of skin breakdown. During rehabilitation hospitalization, patients with spinal cord injury are encouraged to take responsibility for adhering to a regimen of ulcer prevention techniques. There is a lack of objective data demonstrating that strict adherence to a skin care regimen materially contributes to preventing the occurrence of pressure ulcers or which activity, if any, substantially decreases recurrence. Conversely, there is no published evidence that failure to practice these techniques on a regular basis is associated with the occurrence of pressure ulcers.

A related issue pertains to predicting individual differences in adherence to regimens of pressure ulcer prevention. Yu-Tzu
$\&$ Catanzaro $^{17}$ pioneered the use of the Health Beliefs Model $^{18}$ to describe factors that predict adherence to skin care regimens. The present study proposes to confirm and extend their work by focusing on variables associated with the Health Beliefs Model to predict adherence to pressure ulcer prevention strategies.

\section{Methods}

Research design

This was a prospective cohort study. Subjects were assigned to one of the two groups: a control group which was interviewed only at the beginning and the end of the study, and an experimental group that was interviewed every 4-6 weeks. The control group served to control for the effects of the repeated subject-observer interactions on pressure ulcer recurrence. The endpoint for each subject was the appearance of a confirmed stage $\mathrm{II}^{19}$ ulcer or 2 years from the start of the urine collections, whichever came first.

\section{Subjects}

Sixty-two male subjects more than 6 months post spinal cord injury and who had at least one stage II pressure ulcer in the past, but whose skin was intact at the moment of entry into the study, were recruited. Fortytwo subjects were assigned to the experimental group and 20 to the control group. Informed consent according to the Institutional Review Board for Human Subject Research was obtained. Subjects with an existing pressure ulcer, brain injury, or a chronic disease that affects protein metabolism were excluded. The population was all male to avoid any possible effect that female hormone cycles might have on collagen turnover. All subjects were living in the community.

\section{Procedures}

All subjects were interviewed in person at the start of the study. The interview ascertained demographic information, number of 
previous ulcers and how they were managed, knowledge regarding pressure ulcer prevention activities, and pertinent data regarding the subjects' family and home situation, living arrangements, current vocational and/or educational activities, and usual skin care practices. The hospital medical chart, when available, was used to confirm the subjects' medical history.

At the time of the initial interview the subject provided a 24 hour urine sample for the determination of glu-gal Hyl, gal Hyl, calcium, and creatinine concentration. Subsequently, members of the experimental group provided a 24 hour urine sample and completed a questionnaire that emphasized skin care practices in the preceding 24 hours and in the 2 preceding days and ascertained any changes in the living arrangements. The follow up urine samples and interviews were obtained on a random schedule of between 4 and 6 weeks apart.

The biochemical determinations have been described previously. ${ }^{15}$ Briefly, the hydroxylysine glycosides were quantitated in an amino acid analyzer column filled with a crosslinked sulfonated styrene copolymer resin; the eluent was lithium citrate and the color reagent was ninhydrin. Glycoside concentration was expressed as micromoles per gram of creatinine. Creatinine was measured by the Jaffe reaction.

\section{Data analysis}

Descriptive statistics and contingency table analyses were performed with the help of Minitab, a statistical program for the personal computer. Probabilities of 0.05 or less were deemed statistically significant.

\section{Results}

Two of the subjects who completed the initial interview and signed the consent form, failed to provide a urine sample. The cohort then consisted of 40 experimental subjects and 20 controls. The two groups were similar in their physical characteristics and the mean values of the biochemical determinations (Table I and II), but the proportion of subjects lost to follow up was greater in the control group. Two of the controls died from causes unrelated to pressure ulcers; two others were discovered to have an ulcer prior to the start of the study; and three others failed to provide the second urine sample at the end of the study. Among the experimental group, one subject consistently failed to follow the correct procedure for collecting the 24 hour urine sample; one subject went into a deep depression and had to be hospitalized; two subjects dropped out of the study for lack of time; one subject was dropped because of antisocial behavior towards the interviewer; and one subject was hospitalized and underwent a surgical procedure for a kidney infection. The proportion of subjects that developed ulcers in the control and experimental groups was similar, $25 \%$ of controls and $28 \%$ of experimentals (Table I). The appearance of ulcers among the experimental subjects was spread out throughout the study period; while among the controls, most of the ulcers appeared within the first 6 months (Figs 1,2).

A total of 47 subjects completed the study protocol. Sixteen had developed an ulcer and 31 had not. Age, age at onset of injury, race and years since injury were not significantly different among those who did or did

Table I Description of initial cohort (a)

\begin{tabular}{lcccc}
\hline & Controls $(n=20)$ & $\%$ & Experimentals $(n=40)$ & $\%$ \\
\hline Injury at or above T6 & 14 & 70 & 30 & 75 \\
Injury below T6 & 6 & 30 & 10 & 25 \\
White & 15 & 75 & 24 & 60 \\
Black & 5 & 25 & 10 & 25 \\
Hispanic & 0 & 0 & 4 & 10 \\
Other & 0 & 0 & 2 & 28 \\
Developed ulcer & 5 & 25 & 6 & 11 \\
Lost to follow up & 7 & 35 & & 5 \\
\hline
\end{tabular}


Table II Description of initial cohort (b)

\begin{tabular}{|c|c|c|}
\hline & Controls $(n=20)$ & Experimentals $(n=40)$ \\
\hline Age (years) & $37.4 \pm 0.0$ & $36.3 \pm 1.5$ \\
\hline Height $(\mathrm{m})$ & $1.83 \pm 0.02$ & $1.83 \pm 0.01$ \\
\hline Weight (kg) & $78.0 \pm 3.8$ & $71.7 \pm 2.0$ \\
\hline BMI & $23.3 \pm 1.2$ & $21.7 \pm 0.6$ \\
\hline Age at onset & $26.3 \pm 2.1$ & $24.9 \pm 1.4$ \\
\hline Years since injury & $11.1 \pm 1.8$ & $11.3 \pm 1.4$ \\
\hline No. of previous ulcers & $2.9 \pm 0.5$ & $3.1 \pm 0.5$ \\
\hline Urinary creatinine $(\mathrm{g} / 24 \mathrm{~h})$ & $1.23 \pm 0.14$ & $1.14 \pm 0.11$ \\
\hline Urinary calcium $(\mathrm{mg} / 24 \mathrm{~h})$ & $98.8 \pm 15.5$ & $87.9 \pm 14.0$ \\
\hline $\begin{array}{l}\text { Initial glu-gal Hyl } \\
(\mu \mathrm{mol} / \mathrm{g} \text { creatinine })\end{array}$ & $31.3 \pm 7.0$ & $32.1 \pm 13.2$ \\
\hline $\begin{array}{l}\text { Final glu-gal Hyl } \\
(\mu \mathrm{mol} / \mathrm{g} \text { creatinine })\end{array}$ & $80.9 \pm 30.0$ & $57.6 \pm 12.7$ \\
\hline
\end{tabular}

Means \pm standard error mean.



Figure 1 Time from entry into study to appearance of stage II ulcer (control subjects). Time is expressed in years and fractions of years.

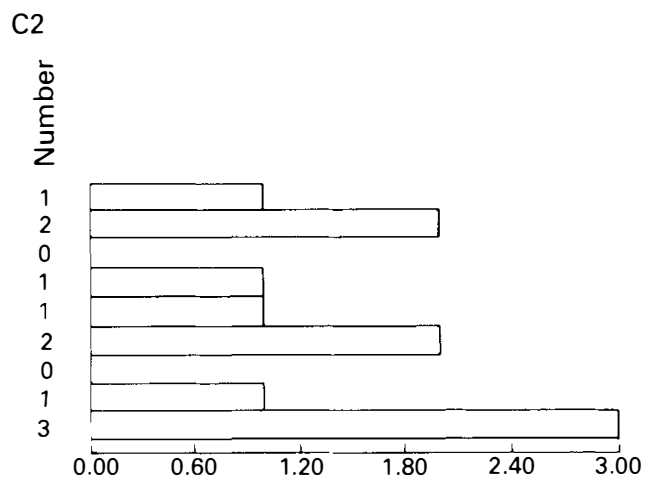

Figure 2 Time from entry into study to appearance of stage II ulcer (experimental subjects). Time is expressed in years and fractions of years. not develop an ulcer (Tables III, IV). The subjects who developed ulcers tended to have had more ulcers previously and to have higher concentrations of glu-gal $\mathrm{Hyl}$ in their initial urine sample. They also had significantly higher concentrations of glu-gal $\mathrm{Hyl}$ in their last urine sample $(p=0.001)$ (Table III). Fluctuations in the urinary concentration of glu-gal Hyl rarely reached more than two or three times the usual concentration in subjects that did not develop ulcers. The mean urinary concentration of glu-gal $\mathrm{Hyl}$ for subjects with a spinal cord injury of more than 6 months duration and no skin lesions is approximately $24 \mu \mathrm{mol} / \mathrm{g}$ creatinine. ${ }^{16}$ Subjects that did develop ulcers sometimes reached a peak concentration of 10 times the usual concentration. The time lapse from the peak glu-gal Hyl excretion to the appearance of a break in the skin varied between 2 and 5 months with a mean of 2.5 months (Figs 3, 4).

Three contingency tables were constructed to determine which screening criteria would be the best predictor of risk of developing an ulcer. The first contingency table used the occurrence of at least one urine sample with a concentration of glu-gal Hyl of more than $100 \mu \mathrm{mol} / \mathrm{g}$ creatinine.

The second contingency table used the ratio of the concentrations of glu-gal Hyl to gal $\mathrm{Hyl}$ in the urine as the screening tool. This ratio is usually less than 2 . A ratio of 3.5 , in at least one urine sample, was used as the cut off point. 
Table III Characteristics of subjects in relation to ulcer incidence (a)

\begin{tabular}{lcccc}
\hline & $\begin{array}{c}\text { Developed ulcer } \\
(n=16)\end{array}$ & $\%$ & $\begin{array}{c}\text { Did not develop ulcer } \\
(n=31)\end{array}$ & $\%$ \\
\hline Injury at or above T6 & 11 & 69 & 21 & 68 \\
Injury below T6 & 5 & 31 & 10 & 32 \\
White & 10 & 63 & 24 & 77 \\
Black & 4 & 25 & 6 & 19 \\
Hispanic & 1 & 6 & 1 & 3 \\
Other & 1 & 6 & 0 & 0 \\
\hline
\end{tabular}

Table IV Characteristics of subjects in relation to ulcer incidence (b)

\begin{tabular}{lcc}
\hline & $\begin{array}{c}\text { Developed ulcer } \\
(n=16)\end{array}$ & $\begin{array}{c}\text { Did not develop ulcer } \\
(n=31)\end{array}$ \\
\hline Age (years) & $39.8 \pm 2.7$ & $36.9 \pm 1.7$ \\
Height $(\mathrm{m})$ & $1.87 \pm 0.02$ & $1.82 \pm 0.01$ \\
Weight $(\mathrm{kg})$ & $75.6 \pm 3.4$ & $74.0 \pm 2.9$ \\
BMI & $21.8 \pm 1.1$ & $22.3 \pm 0.9$ \\
Age at onset & $27.5 \pm 2.6$ & $24.5 \pm 1.6$ \\
Years since injury & $12.3 \pm 2.6$ & $12.4 \pm 1.5$ \\
No. of previous ulcers & $3.7 \pm 0.7$ & $2.5 \pm 0.5$ \\
Urinary creatinine $(\mathrm{g} / 24 \mathrm{~h})$ & $1.07 \pm 0.11$ & $98.9 \pm 16.6$ \\
Urinary calcium $(\mathrm{mg} / 24 \mathrm{~h})$ & $60.4 \pm 8.1$ & $19.5 \pm 3.8$ \\
Initial glu-gal Hyl & $56.2 \pm 30.6^{\mathrm{a}}$ & $35.8 \pm 8.4$ \\
$\quad(\mu$ mol/g creatinine $)$ & $116.3 \pm 29.1^{\mathrm{b}}$ & \\
Final glu-gal Hyl & & \\
$\quad(\mu$ mol/g creatinine $)$ & &
\end{tabular}

${ }^{\mathrm{a}} p=0.116 ;{ }^{\mathrm{b}} p=0.001$.

Means \pm standard error of mean.

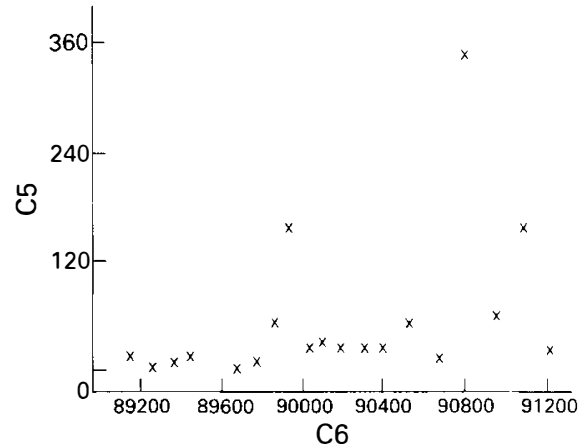

Figure 3 Glu-gal Hyl excretion vs time (subject that developed ulcer). C5: micromoles of glugal per gram of creatinine. C6: date of sample expressed in decimal years; 1 year $=1000$ units. ${ }^{20}$

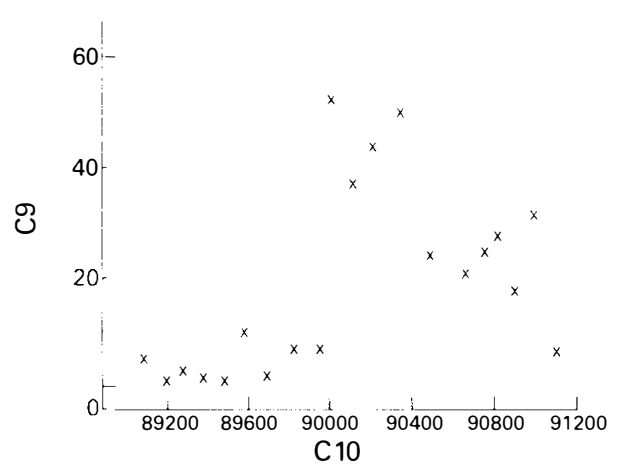

Figure 4 Glu-gal Hyl excretion vs time (subject that did not develop ulcer). C9: micromoles of glu-gal Hyl per gram of creatinine. C10: date of sample expressed in decimal years; 1 year $=$ 1000 units. ${ }^{20}$ 
The third contingency table combined the two screening tools from the two previous tables (Table V). If a subject had at least one urine sample with a glu-gal Hyl concentration of more than $100 \mu \mathrm{mol} / \mathrm{g}$ creatinine and one urine sample with a glu-gal $\mathrm{Hyl}$ to gal Hyl ratio of more than $3.5: 1$, his risk of developing an ulcer was 4.46 times greater than that of a subject who did not meet either condition. Both the negative and positive predictive values were high, $80 \%$ and $70 \%$ respectively. Since one of the cells had an expected count of less than 5, probability was assessed by means of Fisher's exact test. This gave a 0.02 for the probability that these results could be expected from random variation.

Analyses of the behavioral indicators of pressure ulcer risk were based on the responses of the 62 original participants to the oral questionnaire. Questions were designed to elicit the subjects' spontaneous responses regarding pressure ulcer prevention as well as information regarding their beliefs about traditional prevention techniques. Subjects were asked if they believed they were at risk of developing pressure ulcers in the year ahead. Although all of the subjects enrolled into the study had a history of pressure ulcers, $82 \%$ believed that they were not likely to develop another ulcer in the coming year. When asked if they believed pressure ulcers were serious or potentially life threatening, $61 \%$ believed that pressure ulcers were very serious.

In their spontaneous reporting of pressure ulcer prevention practices, $72.5 \%$ cited

Table $\mathbf{V}$ Predictive value of elevated glu-gal Hyl and high ratio

\begin{tabular}{lccc}
\hline & Ulcer & No ulcer & Total \\
\hline $\begin{array}{l}\text { Glu-gal Hyl }>100 \\
\text { ratio }>3.5\end{array}$ & 7 & 3 & 10 \\
$\begin{array}{l}\text { Glu-gal Hyl }<100 \\
\text { ratio }<3.5\end{array}$ & 5 & 20 & 25 \\
Total & 12 & 23 & 35 \\
\hline
\end{tabular}

Sensitivity: $7 / 12=58.3 \%$.

Specificity: $20 / 23=87.0 \%$.

Predictive value positive: $7 / 10=70.0 \%$.

Predictive value negative: $20 / 25=80.0 \%$.

Relative risk: $\frac{7}{12} \div \frac{3}{23}=4.46$. weight shifts or turning as the activity most often performed to prevent pressure ulcers. Avoiding oversitting, hygiene, and skin inspection were reported by $29 \%, 27 \%$, and $24 \%$ respectively. To a lesser extent, subjects reported that the wheechair cushion, careful transfers, diet, topical medications, staying active, and general good health were activities they practiced on a regular basis (Table VI). When presented with a list of prevention strategies and asked to rank them from 'very important' to 'not important', $81 \%$ ranked the wheelchair cushion as 'very important', 77\% ranked hygiene as 'very important', and $74 \%$ ranked weight shifts/turns as 'very important'. Skin inspection was 'very important' to $69 \%$ of the subjects (Table VII).

There were no significant differences between the subjects who developed pressure ulcers and those who did not with regard to their perception of the importance of the various prevention strategies, their beliefs about their risk of developing pressure ulcers, or their beliefs about the serious nature of this complication of their spinal cord injury. However, there were other behavioral indicators that differed between the individuals who developed ulcers and those who did not. There was a significant correlation $(p=0.02)$ between the number of past pressure ulcers and the person's belief that he was at risk of developing pressure ulcers. Those who believed they were less likely to develop an ulcer had had

Table VI Methods of preventing pressure sores: spontaneous responses (62 subjects)

\begin{tabular}{lcc}
\hline Method & $\begin{array}{c}\text { Number of } \\
\text { subjects' } \\
\text { responses }\end{array}$ & \\
\hline Weight shifts/turning & 45 & 72.5 \\
Avoid oversitting & 18 & 29 \\
Hygiene & 17 & 27 \\
Skin inspection & 15 & 24 \\
Wheelchair cushion & 13 & 21 \\
Careful transfers & 11 & 18 \\
Diet & 8 & 13 \\
Oils/topicals & 7 & 11 \\
Stay active/move/exercise & 7 & 11 \\
General health/weight/fluids & 4 & 6 \\
Other & 8 & 13 \\
\hline
\end{tabular}


Table VII Behavioral indicators of pressure sore prevention and their importance (62 subjects)

\begin{tabular}{|c|c|c|c|c|c|c|c|c|}
\hline \multirow[t]{2}{*}{ Indicator } & \multicolumn{2}{|c|}{ Very important } & \multicolumn{2}{|c|}{ Important } & \multicolumn{2}{|c|}{$\begin{array}{l}\text { Somewhat } \\
\text { important }\end{array}$} & \multicolumn{2}{|c|}{ Not important } \\
\hline & No. & $\%$ & No. & $\%$ & No. & $\%$ & No. & $\%$ \\
\hline Hygiene & 48 & 77 & 11 & 18 & 1 & 2 & 0 & 0 \\
\hline Diet & 20 & 32 & 27 & 43.5 & 10 & 16 & 1 & 2 \\
\hline Skin inspection & 43 & 69 & 15 & 24 & 1 & 2 & 0 & 0 \\
\hline Weight shifts \& turns & 46 & 74 & 12 & 19 & 1 & 2 & 1 & 2 \\
\hline Wheelchair & 26 & 42 & 22 & 35 & 6 & 10 & 2 & 3 \\
\hline Wheelchair cushion & 50 & 81 & 10 & 16 & 0 & 0 & 0 & 0 \\
\hline Fit of clothes & 31 & 50 & 21 & 34 & 6 & 10 & 1 & 2 \\
\hline
\end{tabular}

fewer occurrences in the past. In addition, there was a significant difference in the number of previous pressure ulcers between the two groups. The average number of past pressure ulcers for the subjects who developed an ulcer was 4.64; the average number of past pressure ulcers for the subjects who did not develop an ulcer was 2.15 $(p=0.002)$. Although there was an association between smoking and pressure ulcer development and between unemployment and pressure ulcer development, these factors did not reach statistical significance.

\section{Discussion}

The association between unrelieved pressure on some bony prominence of the body and the development of pressure ulcers has been extensively examined. ${ }^{21-25}$ But the association between some metabolic alterations accompanying SCI and the development of pressure ulcers has not received as much attention. The fact that collagen metabolism is altered by SCI is well known. ${ }^{10,11}$ The bone loss that follows SCI is a consequence of this. ${ }^{26}$ Collagen is also lost from the $\operatorname{skin}^{14}$ making it more susceptible to damage from pressure. The fact that the increase in the urinary excretion of the collagen metabolite, glu-gal $\mathrm{Hyl}$, starts before an overt sign of pressure ulcer is evident, can be an aid to prevention. The results of this study demonstrate a significant statistical association between increased excretion of glu-gal Hyl and appearance of a stage II pressure ulcer. The fact that glu-gal Hyl excretion rises before there is a break in the skin may be an indication that the collagen in the dermis has started to break down. This agrees with the widely held view that skin breakdown starts in the deep layers of the skin and/or muscle and works its way up to the surface. ${ }^{27}$

A larger study with more frequent inspection of the skin and more frequent determinations of the urinary concentration of hydroxylysine glycosides is needed to assess more closely the temporal relationship between the start of the rise of the glu-gal Hyl excretion and the appearance of the stage II pressure ulcer.

It is evident that there is a discrepancy between what persons with spinal cord injury know about pressure ulcer prevention and what they are doing in practice to reduce their risk of developing this serious complication. In addition, it appears that what knowledge about pressure ulcer prevention has been retained is incomplete and has not been translated into effective strategies for preventing recurrence. Pressure ulcer prevention education programs designed for an inpatient population during rehabilitation are infrequently evaluated for their effectiveness. Furthermore, it is not known to what extent the information about pressure ulcer prevention is retained over time by these individuals, or their caregivers, once they leave the rehabilitation hospital and are reintegrated into the community. It is interesting to note that none of the participants in this study asked for either additional information about skin care or to be reevaluated for pressure related problems. Physicians, therapists and other re- 
habilitation specialists are experiencing the effects of shorter lengths of hospital stays for patients with even the most severe physical impairments. Many patients are discharged having achieved medical stability and only a modest degree of functional independence. Educational programs that promote pressure ulcer prevention should not be limited to the first rehabilitation experience. They should be incorporated into subsequent rehabilitation hospitalizations, where advanced skills training occurs, or follow up outpatient clinic visits where potential problems are identified. Periodically monitoring the urinary excretion of glu-gal $\mathrm{Hyl}$ and gal $\mathrm{Hyl}$ will provide an objective assessment of pressure ulcer risk that will serve to reinforce the educational program and impress upon the patient the seriousness of the risk.

\section{Acknowledgement}

This study was supported by Grant H133B80020-88A from the National Institute on Disability and Rehabilitation Research.

\section{References}

1 Gosnell DJ (1973) Assessment tool to identify pressure sores. Nurs Res 22: 55-59.

2 Richardson RR, Meyer PR (1981) Prevalence and incidence of pressure sores in acute spinal cord injuries. Paraplegia 19: 235-247.

3 Young JS, Burns PE (1981) Pressure sores and the spinal cord injured. SCI Digest 3: 11-23.

4 Wharton GW, Milani JC, Dean LS (1987) Pressure sore profile: Cost and management. ASIA Abstracts Digest 1987: 115-119.

5 Krouskop TA, Noble PC, Garber SL, Spencer WA (1983) The effectiveness of prevention management in reducing the occurrence of pressure sores. J Rehabil Res Dev 20: 71-83.

6 Lovett PA, Bridle MJ (1986) Your Skin: An Owner's Manual. University of Virginia, Charlottesville.

7 LaMantia JG, Hirschwald JF. Goodman CL, Wooden VM, Delisser O, Staas Jr WE (1987) A program design to reduce chronic readmissions for pressure sores. Rehabil Nurs 12: 22-25, 16.

8 Noble PC (1981) The prevention of pressure sores in persons with spinal cord injuries. World Rehabilitation Fund Monograph No. 11. World Rehabilitation Fund, International Exchange of Information in Rehabilitation, New York.

9 Rothery FA (1989) Preliminary evaluation of a pressure clinic in a new spinal injuries unit. Paraplegia 27: 36-40.

10 Claus-Walker J, Halstead LS (1982) Metabolic and endocrine changes in spinal cord injury: III. Less quanta of sensory impact plus bedrest and illness. Arch Phys Med Rehabil 63: 628-631.

11 Claus-Walker J, Halstead LS (1982) Metabolic and endocrine changes in spinal cord injury: IV. Compounded neurologic dysfunctions. Arch Phys Med Rehabil 63: 632-638.

12 Segrest JP, Cunningham LW (1970) Variations in human urinary O-hydroxylysyl glycoside levels and their relationship to collagen metabolism. J Clin Invest 49: 1497-1509.

13 Askenasi R (1974) Urinary hydroxylysine and hydroxylysyl glycoside excretion in normal and pathologic states. J Lab Clin Med 83: 673-679.

14 Claus-Walker J, Singh J, Leach CS, Hatton DV, Hubert CW, DiFerrante N (1977) The urinary excretion of collagen degradation products by quadriplegic patients and during weightlessness. J Bone Joint Surg 59A: 209-212.

15 Rodriguez GP, Claus-Walker J (1984) Measurement of hydroxylysine glycosides in urine and its application to spinal cord injury. J Chromatogr 308: 65-73.

16 Rodriguez GP, Clauss-Walker J, Kent MC, Garza HM (1989) Collagen metabolite excretion as a predictor of bone- and skin-related complications in spinal cord injury. Arch Phys Med Rehabil 70: 442-444.

$17 \mathrm{Yu}-\mathrm{Tzu}$ MN, Catanzaro M (1987) Health beliefs and compliance with a skin care regimen. Rehabil Nurs 12: $13-16$.

18 Rosenstock IM (1974) Historical origin of the Health Beliefs Model. Health Education Monograph 2: $329-335$.

19 Shea JD (1975) Pressure sores: classification and management. Clin Orthop 112: 89-100.

20 Cameron N (1984) The Measurement of Human Growth. Croom Helm Ltd, London: 156.

21 Kosiak M (1961) Etiology of decubitus ulcers. Arch Phys Med Rehabil 41: 19-29.

22 Lindan O (1961) Etiology of decubitus ulcers. An experimental study. Arch Phys Med Rehabil 41: 774-783.

23 Fisher SV, Patterson RP (1983) Long term pressure recordings under the ischial tuberosities of tetraplegics. Paraplegia 21: 99-106.

24 Merbitz CT, King RB, Bleiberg J, Grip JC (1985) Wheelchair push-ups: Measuring pressure relief frequency. Arch Phys Med Rehabil 66: 433-439. 
25 Crenshaw RP, Vistnes LM (1989) A decade of pressure sore research: 1977-1987. J Rehabil Res Dev 26: 63-74.

26 Chantraine A (1978) Actual concept of osteoporosis in paraplegia. Paraplegia 16: 51-58.

27 Daniel RK, Priest DL, Wheatley DC (1981) Etiologic factors in pressure sores: An experimental model. Arch Phys Med Rehabil 62: 492-498. 